\title{
Factors Influencing Pupils' Performance in Mathematics at Kenya Certificate of Primary Education in Turkana Central Sub-County, Kenya
}

\author{
Lewis Ngesu ${ }^{1}$, Moses Jamin Simotwo ${ }^{2}$ \\ ${ }^{1}$ Asscoiate Professor, ${ }^{2}$ MED Student \\ University of Nairobi, Nairobi, Kenya
}

\section{ABSTRACT}

The purpose of the study was to investigate factors influencing pupils' performance in Mathematics at Kenya Certificate of primary education (KCPE) in Turkana Central Sub-County, Kenya. The study was informed by the following objectives: to determine the influence of teaching resources in pupils' performance in Mathematics at KCPE, to examine the relationship between teachers' qualification and pupils' performance in Mathematics at KCPE, determine the influence of parents on pupils' performance in Mathematics at KCPE and to establish pupils' attitudes in Mathematics at KCPE Turkana Central Sub-County. The study adopted descriptive survey design. The study adopted a sample size of 266 respondents. Stratified, random and purposive sampling techniques were used by the researcher to sample out the population basing on capacities, group characteristics and progressive records for all the respondents. Questionnaire was administered to the head teachers, teachers and pupils. The questionnaire was issued to the head teachers, teachers and learners. The findings of the study were as follows: that the teaching resources influenced performance in Mathematics; that there was a relationship between teachers' qualification and pupils' performance in Mathematics; that parents influenced pupils' Mathematics performance and that pupil' attitudes influenced performance in Mathematics at KCPE. The study came up with the following recommendations: that the schools should have a well-established library so that pupils have enough teaching and learning resources; the government should increase Mathematics teachers in schools; the government and well-wishers to assist the schools by providing them with more learning and teaching resources, parents should be encouraged to assist their children in
Mathematics achievements by buying them text books and pupils should have a positive attitude so that they may do well in Mathematics.

Keywords: Pupils, Academic performance, Mathematics

\section{INTRODUCTION}

The people's general view of Mathematics is that it is all about computation of numbers. This however, is not an enough picture of this important subject as computation is just but among the necessary tools needed to pursue and merit in Mathematical structures, relations and concepts. Mathematics knowledge is fully essential in the modern world coupled with information age and multiple technological innovations. Proper and comprehensive grasping of Mathematical knowledge therefore is a non-substitutable item to academicians at all levels of their academic and societal life. Effective acquaintance and application of the Mathematics skills and principles guarantees a region/country of reliable citizens while assuring the learners of a future bright enough for career advancement. Despite the subject being one of the longest taught from primary through secondary into some lucrative higher learning courses like engineering and medicine in the Kenyan 8.4.4 system, it has frequently registered unsatisfying results mostly in the final exam (KCPE).

Performance in Mathematics in many countries has been low. Colwell (2000) studied the performance of American students in the international Mathematics tests and noted that they were performing poorly. According to Harris (2007) and Ladd (2008) most experienced Mathematics teachers may be less 
effective than their less experienced counterparts and even their inexperienced colleagues. Despite the effect of earlier career experience, the performance distribution of teachers tend to reveal a considerable overlap in value added scores in both Mathematics and reading. This then raises a concern as to whether the existing effects of experience reflect improvement with experience or causes higher attrition on the less effective counterparts.

According to (2013) majority of Nigerian school children generally dread Mathematics. Most of them consider it difficult, complex and abstract. Worse still, many students do not immediately see the use or applicability of the subject to their lives and to the world of work and so wonder why they should be troubled with the study of the subject. Except as a requirement for admission into institutions of higher learning, most students do not see any other need for Mathematics learning. Unfortunately too, some teachers of Mathematics are either not convinced themselves, or do not consider it needful to let students know the benefits that could be derived from the study of Mathematics beyond being a necessity for entry into colleges, polytechnics and universities.

In Kenya, Mathematics is a compulsory subject in both primary and secondary schools. Being a compulsory subject at high school and among key entry requirements to university, there is a need for academic society to understand the causes of the dismal performance and the possible solutions to the problem. This is the main motivation behind this research with the view that the findings afterwards shall be used to positively transform the society as far as Mathematics is concerned. The art of reading and writing in the African context is a totally imported item that fully revolutionized both thinking and educational systems in the continent. Long before the coming of the white man, Africans had their simple systems of passing education from the elderly to the young-generations. While the teaching strategies set ups appear different, the goals were strictly related (Sifuna, 1994). The earlier education to an African child was viewed as a means of civilization, a tool to eradicate poverty and bring with it socialeconomic development to the nation. A study by Nyabuto (2014) on parental involvement on pupils' performance in Mathematics in public primary schools in Kenya established that parents exert a great influence to their children especially at their early stages of development. Most parents wish their children the best in regard to education. However, some parents are still living in ancient days where they are blinded in that they still believe that education is not a good investment.

Among the factors influencing primary pupils' performance in Mathematics, attitudes are regarded by several researchers, as an important/key factor to be taken into account when attempting to understand and explain variability in student performance in Mathematics ( Mata 2012). At the same time attitude can influence a pupil in two ways, positively or negatively. A positive attitude towards Mathematics reflects a positive emotional disposition in relation to the subject and, in a similar way, a negative attitude towards Mathematics relates to a negative emotional disposition (Mata, 2012).

\section{Methodology}

To achieve the objectives of the study, a descriptive survey was utilized. Descriptive designs are used when the objective is systematic description of facts and characteristics of a given population or sample of the population or area of interest factually and accurately (Kothari, 2004).

The study adopted a sample size of 266 respondents. Stratified, random and purposive sampling techniques were used by the researcher to sample out the population basing on capacities, group characteristics and progressive records for all the respondents. The sample/ size comprised of primary school head teachers, Mathematics subject teachers and pupils. Data was collected by use of a questionnaire.

\section{Data Analysis Techniques}

Data presentation, data analysis, and research findings all tend to run at the same time. This is mainly because the end of one process paves way for the beginning of another. Therefore, in most times, these processes are viewed as one entity. However, in this research, all these facets were viewed individually to aptly illustrate the importance of each facet in the study. Descriptive statistics was adopted to analyze data.

\section{Major findings of the study}

The study established that availability of teaching resources influenced pupils' performance in Mathematics. Further, it was found out most libraries were not well-equipped to support teaching of Mathematics. In this study $59.1 \%$ of the respondents 
affirmed that they did not have enough teaching resources while $73.6 \%$ of the respondents stated that they did not have well-equipped libraries in their schools. This was attributed to pupils misplacing text books and dropping from school an indication that at any given time they did not have enough text books at home and school for revision. It was also established that teachers with fewer years of teaching experience or else young teachers were less effective in the teaching of Mathematics which disagrees with the study carried out by Boyd (2008) which established that fresh teachers from college had their greatest productivity during their first few years on the job after which their performance level tends to level off.

The study further established that there was a significant relationship between the teacher qualification and the pupils' academic performance. It was established that most schools did not have enough teachers meaning that the ratio of teacherpupil relationship is very poor in both primary and high schools. In this study, $45.5 \%$ of the respondents were of the view that schools had enough qualified Mathematics teachers. According to Jepsen (2005) teachers' experience is determined by the training teachers go through and the duration of their teaching significantly determines their efficiency in teaching. From the findings of this research, one would expect that pupils' achievement to be reasonable. Nevertheless, the results were still poor due to unavailability of resources such as text books and perception of pupils that Mathematics was a difficult subject. To post better results, teachers used participatory approach and revisions as a way of improving mean grades. These strategies, in most cases were pegged on teachers' qualifications with most of those with more years of teaching experience and higher qualifications posting good results in Mathematics. The findings also indicated that $81.8 \%$ of the respondents were of the opinion that teachers used right strategies in planning and teaching of Mathematics. This is an indication that for better achievement in Mathematics, teachers need the right qualification as well as use of the right strategies in classroom.

In connection with parent's contribution to good performance in Mathematics, the study established that most parents did not assist their children at home. This was the case because most parents had not attained high level of education. However, it was noted at a very small scale that some parents motivated their children to work harder. To some extend this study concurs with the study by Nyabuto (2014) in his findings on parental involvement on pupils' performance in Mathematics in Public Primary Schools in Kenya which showed that parents exert a great influence to their children especially at their early stages of development. Jacobs (2004), affirms that children's perceptions of their abilities in Mathematics are directly influenced by parents' beliefs about their children's academic competencies, however, this study reveals that parents do not view boys performance as being better than girls.

The study established that there was no significant difference among girls and boys in their perception towards teaching and learning of Mathematics. The finding does not correspond with the findings by Sara et al. (2011) who affirmed that parents believed that their sons' Mathematical ability was higher than their daughters. This result explains why some girls are also doing well in Mathematics than boys in some instances. This findings corresponds with the study by Mata (2012) who found out that attitude can influence a pupil in two ways, positively or negatively. A positive attitude towards Mathematics reflects a positive emotional disposition in relation to the subject and, in a similar way, a negative attitude towards Mathematics relates to a negative emotional disposition. Twoli (1986) further supports this study asserting that there is a relationship between achieved grades in earlier examinations at same level and attitudes formed by students towards learning sciences and Mathematics. $88.2 \%$ of the respondents also noted that the best pupils did Mathematics to the fullness due to their positive attitude towards Mathematics.

\section{Conclusion}

Inadequate teaching and learning resources influenced to a larger extent pupils' performance in Mathematics at KCPE. This situation is worsened by parents reluctance to buy some essential text books for pupils. Further, lack of well-stocked libraries is a major impediment to good performance in Mathematics discipline. The study also established that there was a relationship between teachers' qualification and pupils' performance in Mathematics. Some students perceived Mathematics discipline as a difficult subject and therefore teachers must change this mind set in order to post good results in the subject. 
Boys seem to do better than girls in Mathematics. However, this narrative must be addressed in line with sustainable development goals especially on gender equity. The notion that Science discipline are males dominated should be discouraged at all levels of learning and that the girl child should be encouraged to work towards perfection in all subjects.

\section{Recommendations}

The study recommends that primary schools should have well-established libraries that have enough teaching and learning resources for Mathematics. These libraries should be supervised by staff with the relevant qualifications in order to offer appropriate guidance to students who may be having challenges.

The Ministry of Education through the Teachers Service Commission should consider recruiting more teachers of Mathematics in primary schools. This will go a long way in addressing some of the problems associated with this subject. To achieve better results, the Government and other sponsors should also increase funding to facilitate schools to buy more teaching materials and resources.

\section{References}

1. Harris, D. N. (2007). Teacher Training, Teacher Quality and student Performance. The urban Institute.
2. Jacobs, B. A. (2004). The Use of Geospatial Technologies to Increase Students' Spatial Abilities. Reseach paper.

3. Kothari, C. R. (2004). Research Methodology: Methods and Techniques (2nd Ed.). New Yolk. New Age International limited.

4. Ladd, H. F. (2008). Value added Modelling of teacher credentials: policy implications. CALDER Research conference "The Ins and Outs of value added measures in education what research says". washington D. C. Retrieved from http://www.caldercenter.org/upload/sunny_Ladd_ presentation.pdf

5. Mata, M. D. (2012). Attitudes towards Mathematics: Effects of Individual, Research article, 6 .

6. Nyambuto, A. N. (2014). Parental Involvement on Pupils' Performance in Mathematics in. Journal of Educational and Social Research.

7. Oka for, C. F. (2013). Nigerian School Children and Mathematics Phobia: American Journal of Educational Research.

8. Sifuna, D. N. (1994). An introductory History of Education. Nairobi: Nairobi University Press.

9. Twoli, W.N. (1986). Sex difference in Science Achirvement among Secondary Schools Students in Kenya. Flinders University Of outh Australia: Unpublished $\mathrm{PhD}$ Thesis. 